Whitney $U$ test) in both groups. In the VBC group time between decision to treat until funding approval obtained was measured and overall saving by all estimated drug cost was calculated.

Results 122 patients were discussed at VBC - 75 started a biologic (50 new, 25 switched) and 6 entered a clinical trial. The remaining 41 were agreed as unsuitable for a biologic table 1 .

Table 1. Patient not suitable for biologics through VBC IFR: individual funding requests, cDMARDs: Conventional disease modifying ant rheumatic drugs.

\begin{tabular}{lcc}
\hline Reasons for not receiving biologic & $(\mathrm{n}=41)$ & $\%$ \\
\hline IFR application (rejected) & 6 & $12.1 \%$ \\
Patient factor & 5 & $12.1 \%$ \\
Disease activity not meeting NICE criteria & 22 & $53.60 \%$ \\
Alternative treatment offered (eg: cDMARDs) & 6 & $14.60 \%$ \\
Other ${ }^{*}$ & 2 & $4.8 \%$ \\
\hline
\end{tabular}

*1 recurrent infection, 3 did not do their screening test, 1 did not do the recommended vaccination.

${ }^{\star *} 1$ relocated, 1 was referred to gastroenterology team

Comparing groups 69 patients (missing data $=6$ ) waited an average of 35 days (median 27 days) to start a biologic vs 105 average days (median 85) pre VBC for 120 patients ( $U$ is 1033 , $p$-value is < .00001 two tailed).

In the VBC group average delay occurred as follows: referral to VBC meet 14 days $(n=74)$, discussion to funding approval 9 days $(n=69)$, medication receipt by homecare 10 days $(n=64)$ and first order 11 days $(n=46)$.

We assume that in our clinic pre VC and, indeed, in the majority of UK Rheumatology Departments about $90 \%$ of patients recommended for a biologic by a specialist eventually ends up taking that medication and given that assumption potential costs savings with this model are estimated as equivalent to 35 patients (approx. £140K/ yr. - drug costs savings calculated vs current cheapest option, SB4 (£4080/yr)). Conclusion: Our study highlights that transforming biologic prescribing with a one-step virtual MDT clinic improves efficiency, significantly reduces patient access time and should ensure the most cost- effective treatment is agreed. Integration of the local research team in the VC allows eligible patients to be recruited for clinical trials where available offering further NHS cost savings. The VC creates a reliable, excellent training environment to maintain and enhance specialist knowledge and to deliver high standards of patient care.

Disclosure of Interests None declared

DOI: 10.1136/annrheumdis-2019-eular.454

\section{AB1338 PATIENT EDUCATION IN PSORIATIC ARTHRITIS : ADDRESSING AN UNMET NEED}

Keziah Austin ${ }^{1}$, Nia Jones ${ }^{2}$, Roopa Prasad ${ }^{1}{ }^{1}$ University Hospitals Bristol NHS Foundation Trust, Department of Rheumatology, Bristol, United Kingdom; ${ }^{2}$ University Hospitals Bristol NHS Foundation Trust, Department of Medicine, Bristol, United Kingdom

Background: Patient education should be integral to the care of people with inflammatory arthritis [1]. Research suggests that the majority of patients with Psoriatic Arthritis (PSA) would like to receive education about their condition [2]. There are limited studies in PsA but randomised controlled trials in rheumatoid arthritis have demonstrated that patient education improves compliance to medication [3], disease specific knowledge [4] and coping mechanisms [5]. In our department, patient education in PsA was recognised as an unmet need.

Objectives: To pilot an educational session for PsA patients, to assess whether this improved patients' understanding of their condition, and to determine whether an education programme would be a useful adjunct to patient care.

Methods: Adult PsA patients attending their rheumatology clinic appointments were asked to complete a short survey on whether they would be interested in attending an education session and the aspects they would like to have covered. Those who expressed interest were invited to attend a 2.5 hour multidisciplinary team (MDT) session which covered 1) a general overview of PsA; 2) medications used in PsA; 3 ) the role of physiotherapy and occupational therapy; 4) flares and self management. Patients were asked to evaluate their knowledge or understanding before and after each topic covered, on the same day, using a series of 1-10 Likert scales. They were specifically asked whether they found the education session helpful; whether they would recommend it to other PsA patients; whether they would be interested in developing a PsA patient support group.

Results: 25 patients were invited to the session and 9 patients attended There were 5 males and 4 females, across a wide range of age categories. There were statistically significant improvements in all topics covered including a mean improvement of $120 \%$ in how well informed patients felt about PsA in general $(p<0.0001)$; a mean improvement of $79 \%$ in confidence in accessing help from the MDT $(p<0.01)$; a mean improvement of $211 \%$ in how well informed patients were about medications available $(p<0.0001)$; a mean improvement of $86 \%$ in confidence in selfmanaging a flare $(p<0.0001)$. All patients found the session helpful overal and all patients stated they would recommend it to others. Several patients expressed interest in developing a PsA patient support group.

Conclusion: All PsA patients demonstrated a greater awareness and understanding of their condition following a 2.5 hour education session. This study indicates that an education programme is a useful and impor tant adjunct to patient care and supports extending this to the wider PsA patient population.

\section{REFERENCES}

[1] Zangi HA, Ndosi M, Adams J, Andersen L, Bode C, Bostrom C, et al. EULAR recommendations for patient education for people with inflammatory arthritis. Ann Rheum Dis. 2015; 74(6):954-62

[2] Dragoi RG, Ndosi M, Sadlonova M, Hill J, Duer M, Graninger W, et al. Patient education, disease activity and physical function: can we be more targeted? A cross sectional study among people with rheumatoid arthritis, psoriatic arthritis and hand osteoarthritis. Arthritis Res Ther. 2013;15(5): R156

[3] Ravindran V \& Jadhav R. The effect of rheumatoid arthritis disease educa tion on adherence to medications and follow up in Kerala, India. J Rheumatol. 2013;40(8):1460-61

[4] Lovisi Neto BE, Jennings F, Barros Ohashi C, Silva PG \& Natour J. Evaluation of the efficacy of an educational programme for rheumatoid arthritis patients. Clin Exp Rheumatol. 2009;27(1):28-34

[5] Giraudet-Le Quintrec J, Mayoux-Benhamou A, Ravaud P, Champion K Dernis E, Zerkak, et al. Effect of a collective educational program fo patients with rheumatoid arthritis: a prospective 12-month randomized controlled trial. J Rheumatol. 2007;34(8):1684-91.

Disclosure of Interests: Keziah Austin: None declared, Nia Jones: None declared, Roopa Prasad Consultant for: Was on an Advisory Board for a pharmaceutical company meeting several years ago (unrelated to current abstract submission)., Speakers bureau: Speaker fees for a national psoriatic arthritis meeting in 2017 (unrelated to current abstract submission). DOI: 10.1136/annrheumdis-2019-eular.5990

\section{\begin{tabular}{l|l} 
AB1339 & ONLINE CME IMPROVES ADOPTION OF JAK
\end{tabular} INHIBITORS IN CLINICAL PRACTICE BY RHEUMATOLOGISTS}

Elaine Bell, Robert Mccarthy. Medscape LLC, New york, United States of America

Background: The treatment landscape for RA is evolving rapidly. The JAK inhibitors are oral small molecules that have recently been approved for use in RA.

Objectives: This online CME-accredited educational activity was designed to address the challenges of integrating JAK inhibitors into clinical practice in RA and measure changes in practice

Methods: Non-US rheumatologists, dermatologists and primary care physicians (PCPs) participated in an online activity consisting of a 30-minute video roundtable discussion between 4 experts, with synchronized slides, posted online on August 25 2017. A Planned Change Assessment (PCA) survey (data collected through April 3 2018) with qualitative follow-up interviews was used to measure intent to change and actual change in clinical practice following participation in the activity.

A 2-question PCA survey in multiple choice format, which was administered immediately following the activity, asked

What will you do differently in your practice as a result of participating in this activity?

What do you perceive as barriers to making the above selected changes in your practice?

A follow-up survey sent out approximately 8 weeks later included questions about completed changes and barriers to change. Finally, qualitative telephone interviews were conducted to ask learners why certain changes were selected, whether the changes were made and barriers to making the changes.

Results:

- 287 non-US physicians completed the initial PCA survey and 44 completed a follow-up assessment approximately 8 weeks later, resulting in a matched subset of 37 learners. Qualitative interviews were conducted with 13 learners 
- 274 learners $(96 \%)$ indicated that they intended to make a change as a result of participating in the activity with most learners selecting multiple changes

- The most common intended changes for rheumatologists were using a JAK inhibitor for the first time (65\%) and selecting a JAK inhibitor when oral dosing is preferred (54\%)

- Other than systems barriers such as reimbursement and lack of availability of JAK inhibitors, the most common anticipated barriers to change for rheumatologists related to lack of knowledge about MOA and safety, and lack of confidence in their use

- 44 learners completed the follow-up assessment: 42 (96\%) reported making changes in their clinical practice

- o For rheumatologists, the most common actual changes were using a JAK inhibitor first-line (55\%) and considering a JAK inhibitor when oral dosing is preferred $(54 \%)$

- At follow-up the key barriers reported by rheumatologists related to systems barriers/availability and lack of confidence in using JAK inhibitors

Conclusion: Learners in this activity reported increased knowledge about new treatment options for RA and the MOA of JAK inhibitors. The PCA assessment showed that the activity was most effective at prompting rheumatologists to more frequently consider using a JAK inhibitor as a first-line treatment in appropriate patients. Use of new therapeutics, however, may be challenging due to lack of availability of JAK inhibitors in many countries and financial burdens in others. Further education would help rheumatologists to gain confidence in using JAK inhibitors, overcome knowledge gaps, and meet challenges related to lack of access to JAK inhibitors.

Disclosure of Interests: None declared

DOI: 10.1136/annrheumdis-2019-eular.4047

\section{\begin{tabular}{|l|l}
\hline AB1340 & IMPACT OF THERAPEUTIC PATIENT EDUCATION ON
\end{tabular} THE SAFETY OF PATIENTS ON BIOTHERAPY FOR CHRONIC INFLAMMATORY RHEUMATISM}

BENCHARIF IMEN, Dalila Bendjenna. University Public Hospital of Constantine Rheumatology, Constantine, Algeria

Background: Patients treated with biotherapy should be aware of the specific complications. The acquisition of safety skills is one of the objectives of therapeutic patient education programs in chronic inflammatory rheumatism. $(1,2,4)$

Objectives: Evaluation of the impact of the "EST-RIC" therapeutic patient education program on the safety skills of patients on biotherapy for chronic inflammatory rheumatism.

Methods: Descriptive cross-sectional study evaluating the impact of integration into a therapeutic patient education program on the skills of patients treated in a day hospital at the Constantine rheumatology department for chronic inflammatory rheumatism, using the validated "BioSecure" questionnaire (3)

Results: Of sixty patients, fifty-two patients (86.6\%) completed the questionnaire. Forty-three patients have spondyloarthritis (83\%) (Tab1)

The median Biosecure score was $62.90 / 100$ (SD 10.83). Fifty-two percent of the patients had integrated the therapeutic education program. Their Biosecure score was significantly higher than that of naïve patients with therapeutic education (median score $69 / 100$ in the ETP group versus 58/ 100, p <0.001) (Fig 1). The Bioscure score varied significantly with the lower level of education ( $p<0.0001$ ), in the subgroup of patients with a professional activity $(P=0.008)$ and in patients whose treatment was introduced for less than one year $(p<0.0001)$ and who had a pathology whose diagnosis was less than 5 years $(p<0.008)$

Conclusion: The integration of patients undergoing biotherapy into a specialized program of therapeutic patient education is correlated with a better mastery of theoretical safety skills.

\section{REFERENCES}

[1] Orefice D, Beauvais C, Gossec L, et al. Cross-sectional study of self-care safety skills in 677 patients on biodrugs for inflammatory joint disease. Joint BoneSpine Rev Rhum 2014;81:502-7.

[2] Claudepierre P, Flipo R-M, Sibilia J, et al. Patient's knowledge of their disease: a multicenter study in ankylosing spondylitis. Bone Spine2004; 71: 550-6.

[3] Gossec L, Fautrel B, Flipon E, et al. Tolerance of biotherapies: development and validation of a questionnaire evaluating self-management and patient safety skills: the Biosecure questionnaire. An initiative of the French Rheumatology Society, Therapeutic Education Section. Rev Rhum2013; 80: 479-85.
[4] Meesters JJL, Vliet Vlieland TPM, Hill J, et al. Measuring educational needsamong patients with rheumatoid arthritis using the Dutch version of the Needs Assessment Tool (DENAT). Clin Rheumatol 2009; 28: 1073-7.

Tab 1: Characteristics of the patient

\begin{tabular}{|c|c|c|c|c|c|c|c|}
\hline Charactersistics & & Jitation & & & & & $p$ \\
\hline $\begin{array}{l}\text { Sex }(N=52, N A=0) \\
\text { Women } \\
\text { Men }\end{array}$ & $\begin{array}{l}24 \\
28\end{array}$ & $\begin{array}{l}46 \% \\
54 \%\end{array}$ & $\begin{array}{l}11 \\
16\end{array}$ & $\begin{array}{l}46 \% \\
57 \%\end{array}$ & $\begin{array}{l}13 \\
12\end{array}$ & $\begin{array}{l}54 \% \\
43 \%\end{array}$ & $P=0.159$ \\
\hline $\begin{array}{l}\text { Age (yeors) (N=52, NA=0) } \\
30.0 \\
30.50 \\
>50\end{array}$ & $\begin{array}{l}10 \\
32 \\
10\end{array}$ & $\begin{array}{l}19 \% \\
62 \% \\
19 \%\end{array}$ & $\begin{array}{l}2 \\
17 \\
8\end{array}$ & $\begin{array}{l}20 \% \\
53 \% \\
80 \%\end{array}$ & $\begin{array}{c}8 \\
15 \\
2\end{array}$ & $\begin{array}{l}80 \% \\
46 \% \\
20 \%\end{array}$ & $P=0,005$ \\
\hline $\begin{array}{l}\text { tamily stotus (N=50, NA=2) } \\
\text { single } \\
\text { No single }\end{array}$ & $\begin{array}{l}18 \\
32\end{array}$ & $\begin{array}{l}36 \% \\
64 \%\end{array}$ & $\begin{array}{l}4 \\
23\end{array}$ & $\begin{array}{l}22 \% \\
72 \%\end{array}$ & 14 & $\begin{array}{l}78 \% \\
28 \% \\
\end{array}$ & $P=0.001$ \\
\hline $\begin{array}{l}\text { sechool level (N=51, NA=1) } \\
\text { BACC. } \\
\text { BAC. }\end{array}$ & $\begin{array}{l}38 \\
13\end{array}$ & $\begin{array}{l}74,5 \% \\
25,5 \%\end{array}$ & 18 & $\begin{array}{l}47 \% \\
69 \%\end{array}$ & $\begin{array}{l}20 \\
4\end{array}$ & $\begin{array}{l}53 \% \\
31 \%\end{array}$ & $P=0.105$ \\
\hline $\begin{array}{l}\text { Longuoge mastery (N=50. NA=1) } \\
\text { Non mairse } \\
\text { Moyyen } \\
\text { Motirise }\end{array}$ & $\begin{array}{l}29 \\
12 \\
9\end{array}$ & $\begin{array}{l}58 \% \\
24 \% \\
18 \%\end{array}$ & $\begin{array}{l}13 \\
7 \\
7\end{array}$ & $\begin{array}{l}45 \% \\
58 \% \\
78 \%\end{array}$ & $\begin{array}{l}16 \\
5 \\
2\end{array}$ & $\begin{array}{l}55 \% \\
42 \% \\
22 \%\end{array}$ & $P=0,033$ \\
\hline $\begin{array}{l}\text { protessional status (N=50, NA=2) } \\
\text { AAtive } \\
\text { Non active }\end{array}$ & $\begin{array}{l}30 \\
20\end{array}$ & $\begin{array}{l}60 \% \\
40 \%\end{array}$ & $\begin{array}{c}18 \\
9\end{array}$ & $\begin{array}{l}60 \% \\
45 \%\end{array}$ & $\begin{array}{l}12 \\
11\end{array}$ & $\begin{array}{l}40 \% \\
55 \%\end{array}$ & $P=0.134$ \\
\hline $\begin{array}{l}\text { Pathology }(N=52, N A=0) \\
\text { RA } \\
\text { PA } \\
\text { Autres SA }\end{array}$ & $\begin{array}{l}5 \\
4 \\
43\end{array}$ & $\begin{array}{l}9.6 \% \\
7.7 \% \\
82.7 \%\end{array}$ & $\begin{array}{c}1 \\
3 \\
23 \\
23\end{array}$ & $\begin{array}{l}20 \% \\
75 \% \\
53.5 \%\end{array}$ & $\begin{array}{c}4 \\
1 \\
20\end{array}$ & $\begin{array}{l}80 \% \\
25 \% \\
46.5 \%\end{array}$ & $P=0.263$ \\
\hline $\begin{array}{l}\text { Duration of thiness (N=47, NA=5) } \\
<5 \text { ans } \\
5.10 \text { ans } \\
>10 \text { ans }\end{array}$ & $\begin{array}{l}10 \\
18 \\
19\end{array}$ & $\begin{array}{l}21.3 \% \\
38.3 \% \\
40.1 \%\end{array}$ & $\begin{array}{c}5 \\
7 \\
11\end{array}$ & $\begin{array}{l}50 \% \\
39 \% \\
58 \%\end{array}$ & $\begin{array}{c}5 \\
11 \\
8\end{array}$ & $\begin{array}{l}50 \% \\
61 \% \\
42 \%\end{array}$ & $P=0,126$ \\
\hline $\begin{array}{l}\text { Beginning of blotherapy (N=51) } \\
\begin{array}{l}1 \text { an } \\
1-2 \text { ans } \\
>2 \text { ans }\end{array}\end{array}$ & $\begin{array}{l}20 \\
14 \\
17\end{array}$ & $\begin{array}{l}39.7 \% \\
27.7 \% \\
33.3 \%\end{array}$ & $\begin{array}{l}9 \\
6 \\
11\end{array}$ & $\begin{array}{l}45 \% \\
43 \% \\
65 \%\end{array}$ & $\begin{array}{c}11 \\
8 \\
6\end{array}$ & $\begin{array}{l}55 \% \\
57 \% \\
35 \%\end{array}$ & $P=0.068$ \\
\hline $\begin{array}{l}\text { Adress (N=50, NA=2) } \\
\text { Wliloyo Wlaya } \\
\text { outor Wlaya }\end{array}$ & ${ }_{8}^{42}$ & $\begin{array}{l}84 \% \\
16 \%\end{array}$ & $\begin{array}{l}22 \\
3\end{array}$ & $\begin{array}{l}52 \% \\
37.5 \%\end{array}$ & $\begin{array}{c}20 \\
5\end{array}$ & $\begin{array}{l}48 \% \\
62.5 \%\end{array}$ & $P=0.228$ \\
\hline
\end{tabular}

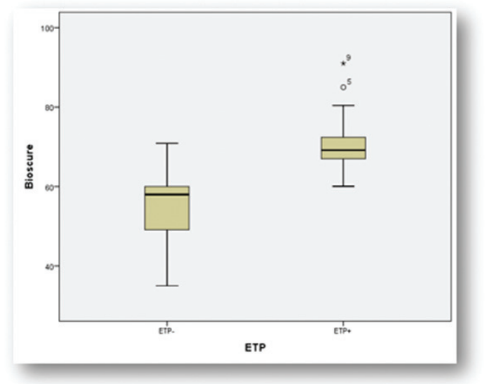

Figure 1:. The median Biosecure score

Disclosure of Interests: None declared

DOI: 10.1136/annrheumdis-2019-eular.5159

\section{AB1341 PUBLIC AWARENESS OF RHEUMATOID ARTHRITIS IN MONGOLIA}

Lkham-Erdene Byambadoo ${ }^{1}$, Nandin-Erdene Danzan ${ }^{1}$, Tsolmon Darisuren ${ }^{1}$, Devshil Zorigt $^{1}$, Enkhjin Bat-Erdene ${ }^{2}$, Davaadulam Enkhbold ${ }^{2}$, Zulgerel Dandii ${ }^{1}$ ${ }^{1}$ Mongolian Rheumatology Association, Ulaanbaatar, Mongolia; ${ }^{2}$ Mongolian National University of Medical Sciences, Ulaanbaatar, Mongolia

Background: Rheumatoid arthritis (RA) is multifactorial, chronic, inflammatory disease which in the absence of early diagnosis can lead to joint destruction and disability. In the last decade, rheumatology has been developed as independent branch in Internal medicine in Mongolia, published rheumatological textbooks. The Mongolian Rheumatology Association has also introduced a RA guideline and conducted training that has led to the use of DMARDs in treatment and improves patient's quality of life is improving in Mongolia. Nevertheless, we have many patients with a late RA diagnosis in Mongolia. In some studies, poor public awareness of RA correlates with high level of disability.

Objectives: To develop understanding about current levels of public awareness of rheumatoid arthritis in patients coming to the outpatient department of the First central hospital in Ulaanbaatar, Mongolia

Methods: This was a cross-sectional descriptive study conducted in the outpatient department of the First central hospital of Ulaanbaatar in Mongolia for 3 days. The study population consisted of adults. Data collection was performed by using questionnaire of developed by the NRAS addressed to assess awareness on RA.

Results: Total 376 persons stood for 3 days in outpatient clinic in First central hospital. 26 of them refused and 350 of them participated our study. The average age of the participants was 37.79. Participants responded, $22 \%$ of them know RA, $78 \%$ of whom do not know 